\title{
Correction to: Towards intellectual freedom in an Al Ethics Global Community
}

\author{
Christoph Ebell ${ }^{1,2} \cdot$ Ricardo Baeza-Yates $^{3} \cdot$ Richard Benjamins $^{4} \cdot$ Hengjin Cai $^{5} \cdot$ Mark Coeckelbergh $^{6} \cdot$ Tania Duarte $^{7}$. \\ Merve Hickok $^{8}$ - Aurelie Jacquet ${ }^{9} \cdot$ Angela Kim $^{10}$. Joris Krijger ${ }^{11}$. John Maclntyre ${ }^{12}$. Piyush Madhamshettiwar ${ }^{13}$. \\ Lauren Mafeo ${ }^{14} \cdot$ Jeanna Matthews ${ }^{15} \cdot$ Larry Medsker $^{16} \cdot$ Peter Smith $^{12} \cdot$ Savannah Thais $^{17}$
}

Published online: 6 May 2021

(c) Springer Nature Switzerland AG 2021

\section{Correction to: Al and Ethics} https://doi.org/10.1007/s43681-021-00052-5

For the above referenced publication, the affiliations of some co-authors were incorrectly published. The correct affiliations have been copied below:

\section{Ricardo Baeza-Yates}

Institute for Experiential AI, Northeastern University, USA

4 Richard Benjamins

Observatorio del impacto social y ético de la inteligencia artificial, Spain

8 Merve Hickok

AIethicist.org, Ann Arbor, MI, USA

The original article can be found online at https://doi.org/10.1007/ s43681-021-00052-5.

Christoph Ebell

christoph.ebell@verticai.org

Tania Duarte

http://www.weandai.org

Merve Hickok

http://www.Alethicist.org

HumanIn Association, Paris, France

2 Verticai Consulting, Geneva, Switzerland

3 Institute for Experiential AI, Northeastern University, Boston, USA

4 Observatorio del impacto social y ético de la inteligencia artificial, Barcelona, Spain

5 School of Computer Science, Wuhan University, Wuhan, People's Republic of China
9 Aurelie Jacquet

Lawyer, Sydney, Australia

10 Angela Kim

Women in AI, Sydney, Australia

13 Piyush Madhamshettiwar

Department of Transport, Victoria, Australia

14 Lauren Maffeo

Washington, DC, USA

Reference 57 should read:

57. Benjamins, R. X., Barbado, A., and Sierra, D.: Responsible AI by Design in Practice. In: Proceedings of the

\footnotetext{
Universität Wien, Wien, Austria

We and AI, London, UK

AIethicist.Org, Ann Arbor, MI, USA

Lawyer, Sydney, Australia

Women in AI, Sydney, Australia

11 Erasmus Universiteit Rotterdam, Rotterdam, The Netherlands

12 Sunderland University, Sunderland, UK

13 Department of Transport, Victoria, Australia

14 Washington, DC, USA

15 Clarkson University, Potsdam, USA

16 George Washington University, Washington, DC, USA

17 Princeton University, Princeton, USA
} 
Human-Centered AI: Trustworthiness of AI Models \& Data

(HAI) track at AAAI Fall Symposium, DC, 2019

The original article has been corrected.
Publisher's Note Springer Nature remains neutral with regard to jurisdictional claims in published maps and institutional affiliations. 